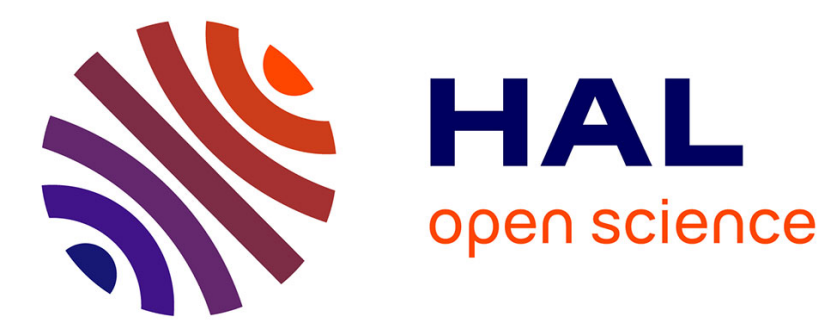

\title{
Can CO2 Turbulent Flux Be Measured by Lidar? A Preliminary Study
}

Fabien Gibert, Grady J. Koch, Jeffrey Y. Beyon, Timothy W. Hilton, Kenneth J. Davis, Arlyn Andrews, Pierre H. Flamant, Upendra N. Singh

\section{- To cite this version:}

Fabien Gibert, Grady J. Koch, Jeffrey Y. Beyon, Timothy W. Hilton, Kenneth J. Davis, et al.. Can CO2 Turbulent Flux Be Measured by Lidar? A Preliminary Study. Journal of Atmospheric and Oceanic Technology, 2011, 28 (3), pp.365-377. 10.1175/2010jtecha1446.1 . hal-01117346

\section{HAL Id: hal-01117346 https://hal.science/hal-01117346}

Submitted on 20 Feb 2015

HAL is a multi-disciplinary open access archive for the deposit and dissemination of scientific research documents, whether they are published or not. The documents may come from teaching and research institutions in France or abroad, or from public or private research centers.
L'archive ouverte pluridisciplinaire HAL, est destinée au dépôt et à la diffusion de documents scientifiques de niveau recherche, publiés ou non, émanant des établissements d'enseignement et de recherche français ou étrangers, des laboratoires publics ou privés. 


\title{
Can $\mathrm{CO}_{2}$ Turbulent Flux Be Measured by Lidar? A Preliminary Study
}

\author{
Fabien Gibert, ${ }^{*,+}$ Grady J. Koch,\# JefFrey Y. Beyon,\# Timothy W. Hilton, ${ }^{+}$ \\ Kenneth J. Davis, ${ }^{+}$Arlyn Andrews, ${ }^{\circledR}$ Pierre H. Flamant, ${ }^{*}$ And Upendra N. Singh ${ }^{\#}$ \\ * Laboratoire de Météorologie Dynamique, Institut Pierre et Simon Laplace, Ecole Polytechnique, Palaiseau, France \\ ${ }^{+}$Department of Meteorology, The Pennsylvania State University, University Park, Pennsylvania \\ ${ }^{\#}$ NASA Langley Research Center, Hampton, Virginia \\ ${ }^{\circledR}$ NOAA/Earth System Research Laboratory, Boulder, Colorado
}

(Manuscript received 19 January 2010, in final form 15 April 2010)

\begin{abstract}
The vertical profiling of $\mathrm{CO}_{2}$ turbulent fluxes in the atmospheric boundary layer (ABL) is investigated using a coherent differential absorption lidar (CDIAL) operated nearby a tall tower in Wisconsin during June 2007. A CDIAL can perform simultaneous range-resolved $\mathrm{CO}_{2}$ DIAL and velocity measurements. The lidar eddy covariance technique is presented. The aims of the study are (i) an assessment of performance and current limitation of available CDIAL for $\mathrm{CO}_{2}$ turbulent fluxes and (ii) the derivation of instrument specifications to build a future CDIAL to perform accurate range-resolved $\mathrm{CO}_{2}$ fluxes. Experimental lidar $\mathrm{CO}_{2}$ mixing ratio and vertical velocity profiles are successfully compared with in situ sensors measurements. Time and space integral scales of turbulence in the $\mathrm{ABL}$ are addressed that result in limitation for time averaging and range accumulation. A first attempt to infer $\mathrm{CO}_{2}$ fluxes using an eddy covariance technique with currently available $2-\mu \mathrm{m}$ CDIAL dataset is reported.
\end{abstract}

\section{Introduction}

The study of transport processes by turbulent fluxes is a key to understanding the exchanges that take place among the various components of the biosphere (i.e., the surface including vegetation and the atmosphere) at different time and space scales. For the past several decades, turbulent flux measurements of scalars have been conducted with in situ probes by using the eddy covariance (EC) technique (Desai et al. 2005). This results in a rather high-accuracy measurement $(\approx 10 \%)$ but with an inherent representativeness limitation to small or local scales. Furthermore, considering the need for large scales both in vertical and horizontal dimensions, it calls for networks of tall towers. Even if the usual height is limited to tens of meters, their deployment is scarce and expensive. The few tall towers that extend several hundreds of meters are suited for vertical sampling in the nocturnal layer (NL) but fail short to sample the daily convective atmospheric boundary layer $(\mathrm{CBL})$ or nocturnal residual layer $(\mathrm{RL})$ with

Corresponding author address: Fabien Gibert, IPSL/LMD Ecole Polytechnique, Palaiseau, France.

E-mail: fabien.gibert@lmd.polytechnique.fr height $h \geq 0.5 \mathrm{~km}$. Only the deployment of instrumented aircraft enables one to profile the turbulent fluxes but with the limitation of requiring dedicated field campaigns.

Having these restrictions in mind, and even knowing that footprint models may enlarge the in situ probe measurement representativeness (Wang et al. 2006), we think it is worth addressing the capability of remote sensors to profile turbulent fluxes in either vertical or horizontal dimensions. To this end, lidar techniques [i.e., elastic backscatter, differential absorption lidar (DIAL), Raman, Doppler] have shown a great capability to profile aerosol particles, minor gas concentration, and wind velocity along the lidar line of sight or in $2 \mathrm{D}$ or $3 \mathrm{D}$. Through combining two of these capabilities (gas concentration and wind velocity), lidars have the potential to make range-resolved flux measurements using an eddy covariance method. Preliminary studies have been conducted using a combination of ground-based (Giez et al. 1999) or airborne (Kiemle et al. 2007) Doppler and DIAL lidars, or aerosol flux using ground-based Doppler and Raman lidars (Engelmann et al. 2008). Moreover, the flexibility of the lidar technique in time averaging and over range accumulation is well suited to address integral scale issues up to several kilometers. 
Presently, we are interested in an application of lidar for $\mathrm{CO}_{2}$ fluxes using the eddy covariance technique. Instead of using two different lidars, one for concentration and one for velocity measurements (see Giez et al. 1999; Kiemle et al. 2007), we propose to use one single $2-\mu \mathrm{m}$ coherent differential absorption lidar (CDIAL) for simultaneous measurements of $\mathrm{CO}_{2}$ concentration and velocity (Gibert et al. 2006). However, one limitation is it requires a large number of independent samples for accurate $\mathrm{CO}_{2}$ concentration measurements. The signal-tonoise ratio (SNR) in coherent (or heterodyne) detection on a single-shot basis is limited to about unity because of the speckle noise. Single-shot SNR can be improved using a speckle diversity technique (Favreau et al.2000) but still requires a large number of samples to achieve high SNR $\left[\approx\left(10^{2}-10^{3}\right)\right]$ as required for $1 \%$ accuracy on absorption optical depth to derive high-accuracy molecular density and mixing ratio. The $2-\mu \mathrm{m}$ CDIAL systems demonstrated a precision of $\sim 1 \%$ for $\mathrm{CO}_{2}$ mixing ratio for an accumulation time of $\sim 30 \mathrm{~min}$ and range resolution of $\sim 1 \mathrm{~km}$ (Koch et al. 2008; Gibert et al. 2008).

The goal of the present paper is (i) to assess the performance and current limitation for $\mathrm{CO}_{2}$ flux measurements using one single DIAL and Doppler lidar and (ii) to derive the specifications of a future instrument to retrieve accurate $\mathrm{CO}_{2}$ fluxes. Section 2 presents the experimental site in Wisconsin with the different instruments (i.e., an instrumented 447-m tower and a ground-based $2-\mu \mathrm{m}$ CDIAL) and the $\mathrm{CO}_{2}$ flux measurement technique. Section 3 presents the meteorological conditions during the 3-day period (i.e., 14-16 June 2007) devoted to field measurements. The $2-\mu \mathrm{m}$ CDIAL for simultaneous $\mathrm{CO}_{2}$ and velocity measurements is presented in section 4 . Section 5 deals with $\mathrm{CO}_{2}$ and vertical velocity fluctuations as inferred by in situ sensors. Section 6 addresses issues of time and space integral scales as reported by Lenschow and Stankov (1986) that result in limitation for time averaging and range accumulation. This process allows deriving the upper bounds to avoid biases in $\mathrm{CO}_{2}$ flux estimates using a 2- $\mu \mathrm{m}$ CDIAL. Section 7 is a first attempt to infer $\mathrm{CO}_{2}$ fluxes using an eddy covariance technique and current $2-\mu \mathrm{m}$ CDIAL dataset. Finally, section 8 deals with the specifications for a future CDIAL to perform accurate $(<50 \%) \mathrm{CO}_{2}$ flux measurements.

\section{Experimental site, instrumentation, and lidar methodology}

\section{a. Instrumentation}

The National Aeronautics and Space Administration (NASA) Langley coherent 2- $\mu$ m DIAL was positioned underneath the $447-\mathrm{m}$ WLEF tall tower $\left(45.945^{\circ} \mathrm{N}\right.$, $90.272^{\circ} \mathrm{W}$ ) in Park Falls, Wisconsin, approximately $40 \mathrm{~m}$ away from the tower's centerline. Two in situ infrared gas analyzers (IRGAs; LiCor Model Li-6251) provide 2-min mean $\mathrm{CO}_{2}$ mixing ratios at six levels above the ground $(11,30,76,122,244$, and $396 \mathrm{~m})$. Turbulent winds, virtual potential temperature, and $\mathrm{H}_{2} \mathrm{O}$ mixing ratio are also measured by three sonic anemometers and other IRGAs at three levels: 30, 122, and $396 \mathrm{~m}$. A groundbased meteorological station also provides net radiation and surface pressure, temperature, and moisture (Berger et al. 2001).

The 2- $\mu$ m CDIAL transmitter is a $90-\mathrm{mJ}, 140-\mathrm{ns}, 5-\mathrm{Hz}$ pulsed Ho, Tm:LuLiF seeded oscillator described in Koch et al. (2004, 2007). The online wavelength of the transmitter is locked onto the side of the $\mathrm{R} 22 \mathrm{CO}_{2}$ absorption line at $2053.204 \mathrm{~nm}$ with a frequency stability of 1.9 MHz, which is needed for unbiased measurements. However, the offline was positioned $0.25 \mathrm{~nm}$ away on weak $\mathrm{H}_{2} \mathrm{O}$ absorption lines, which results in bias that can be corrected as discussed in section 4 . The lidar beam can be scanned to probe the atmosphere in $3 \mathrm{D}$ or vertically pointing at zenith or horizontally. The heterodyne RF signals are digitized on 8 bits at a $500-\mathrm{MHz}$ sampling frequency and stored on a PC. Postprocessing is conducted using both power and velocity estimators (Gibert et al. 2006). The atmospheric return signals are processed range gate by range gate and then accumulated for $N$ shots. The time and range resolutions are $40 \mathrm{~s}$ and $75 \mathrm{~m}$, respectively. As presented in section 1 , the vertical velocity and $\mathrm{CO}_{2}$ profiles are of first interest. In addition, horizontal wind measurements were performed every $30 \mathrm{~min}$.

\section{b. Simultaneous vertical structure, vertical velocity, $\mathrm{CO}_{2}$ mixing ratio, and turbulent flux estimates by 2- $\mu m$ CDIAL}

The height of the convective and the residual (RL) boundary layer are calculated using the second derivative of the backscatter signal profile (Menut et al. 1999). Given the lidar limitation at short range $(150 \mathrm{~m})$, the lidar was able to probe the residual layer at night and most of the convective boundary layer during daytime. The nocturnal boundary layer height (NL) was estimated using the second derivative of $\mathrm{CO}_{2}$ mixing ratio profiles as provided by the WLEF radio tower.

The vertical (or horizontal) velocity component on the lidar line of sight is computed from the mean Doppler frequency shift $\Delta \nu$ due to particle motion in $\Delta z$ :

$$
w=-\lambda \Delta \nu / 2 .
$$

An estimate of a mean $\mathrm{CO}_{2}$ mixing ratio at $z+\Delta z / 2$ is obtained assuming that the on- and off-line probing frequencies are close enough that backscatter and extinction coefficient differences are negligible: 

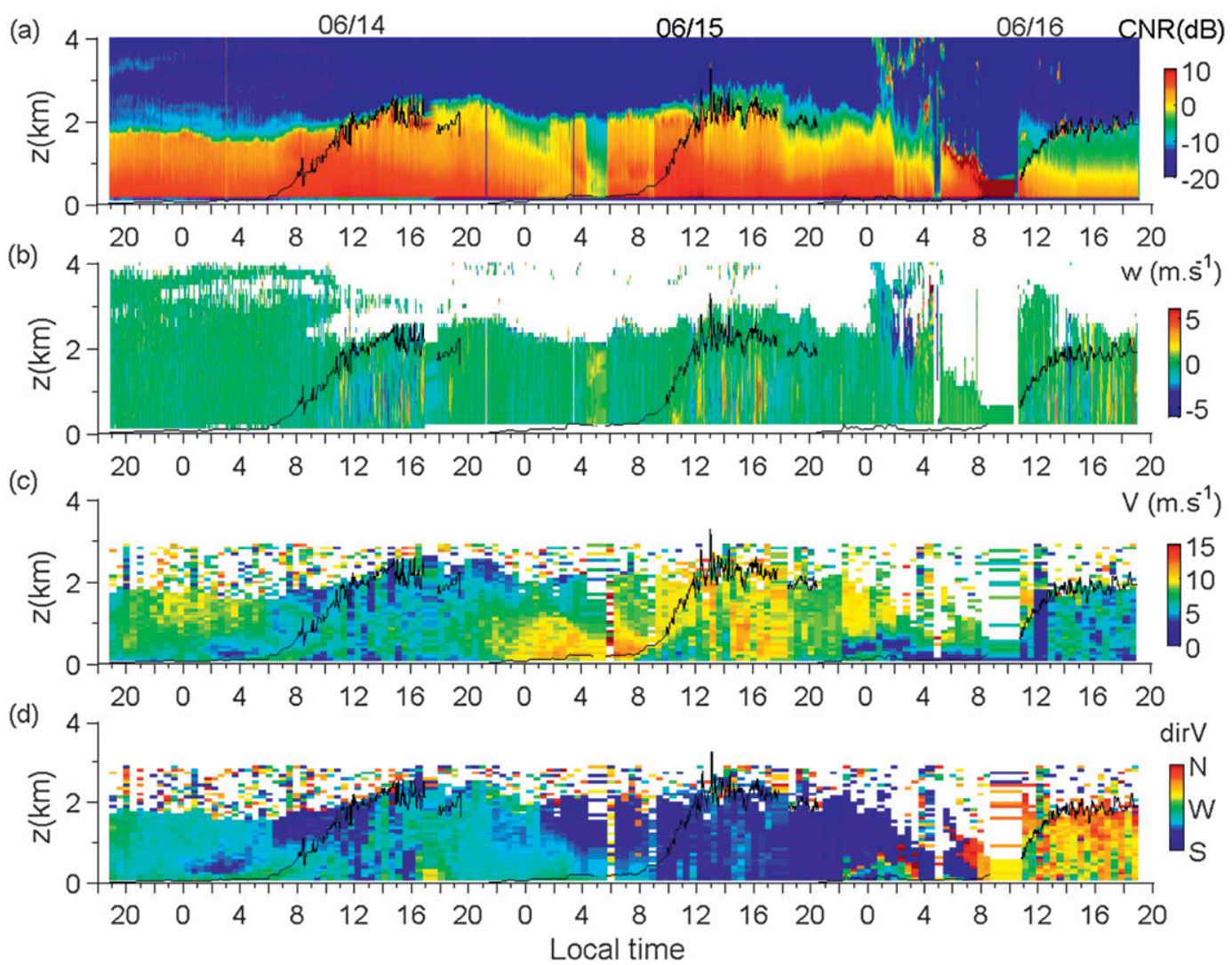

FIG. 1. (a) The off-line carrier-to-noise ratio (CNR), (b) vertical velocity (w), (c) horizontal wind speed (V), and (d) direction (dirV) as a function of the local time. The ABL height is indicated with a black solid line.

$$
\rho_{\mathrm{CO} 2}=\frac{1}{2 n_{\text {air }} \Delta \tilde{\sigma}_{\mathrm{CO} 2}} \ln \left[\frac{P_{\text {off }}(z+\Delta z) P_{\text {on }}(z)}{P_{\text {off }}(z) P_{\text {on }}(z+\Delta z)}\right]+C+D,
$$

where $C=-\rho_{\mathrm{H} 2 \mathrm{O}} \Delta \tilde{\sigma}_{\mathrm{H} 2 \mathrm{O}} / \Delta \tilde{\sigma}_{\mathrm{CO} 2}$ is a corrective term due to the overlap of water vapor absorption line on the off laser line, $\rho_{\mathrm{H} 2 \mathrm{O}}$ is the mean water vapor mixing ratio, $\Delta \tilde{\sigma}$ is the differential cross section, $n_{\text {air }}$ is the dry air density, and $D=\left[\operatorname{SNR}_{\mathrm{on}}^{-2}(z)-\operatorname{SNR}_{\mathrm{off}}^{-2}(z)-\operatorname{SNR}_{\mathrm{on}}^{-2}(z+\Delta z)+\right.$ $\left.\mathrm{SNR}_{\text {off }}^{-2}(z+\Delta z)\right] /\left(4 n_{\text {air }} \Delta \tilde{\sigma}_{\mathrm{CO} 2}\right)$ is a corrective term due to DIAL equation nonlinearity and depends on the off and on SNR [from appendix C in Gibert et al. (2008)].

The differential cross section and dry-air density are computed using the most accurate spectroscopic data (Toth et al. 2006, 2007) and on-site data from the WLEF tower in situ sensors for temperature, pressure, and specific humidity. However, the meteorological sensors measurements are extrapolated up to $3 \mathrm{~km}$ assuming a linear decrease of temperature and an exponential decrease of pressure. Note that $\rho_{\mathrm{H}_{2} \mathrm{O}}$ is assumed to be constant in the atmospheric boundary layer (ABL) above $z>396 \mathrm{~m}$ and negligible in the free troposphere.
To infer a $\mathrm{CO}_{2}$ flux estimate using the eddy covariance method, we need high-frequency measurements of $\mathrm{CO}_{2}$ and velocities. The key question about sampling frequency is presented in section 6 . To avoid any bias in $\mathrm{CO}_{2}$ flux, the lidar time and range resolutions need to be smaller than the vertical and horizontal scales of turbulence. The $\mathrm{CO}_{2} \mathrm{EC}$ flux relies on correlation between the fluctuations of $\mathrm{CO}_{2}$ mixing ratio $\left(\rho_{\mathrm{CO} 2}^{\prime}\right)$ and vertical velocities $\left(w^{\prime}\right)$ due to turbulence only:

$$
F_{\mathrm{CO} 2}=\overline{\overline{\langle w\rangle}}, \overline{\overline{\left\langle\rho_{\mathrm{CO} 2}\right\rangle}}{ }^{\prime}+F_{C},
$$

where the angle brackets and overbar stand for range accumulation and time averaging. As before, $F_{C}=$ $-F_{\mathrm{H} 2 \mathrm{O}} \Delta \tilde{\sigma}_{\mathrm{H} 2 \mathrm{O}} / \Delta \tilde{\sigma}_{\mathrm{CO} 2}$ is a corrective flux term due to partial water vapor absorption in the off-line mode.

\section{Case study}

The field experiments were conducted on three days: 14-16 June 2007, with different synoptic conditions (Fig. 1). 
The sun rises at 0530 and sets at 2030 local time; 14 and 16 June (D14 and D16 hereafter) are characterized by weak wind speed conditions with $V<5 \mathrm{~m} \mathrm{~s}^{-1}$ whereas for 15 June (D15) $V=10 \mathrm{~m} \mathrm{~s}^{-1}$. Cumulus clouds were present during daytime and large entrainment zones (especially for D14 and D15) were observed at the top of the convective boundary layer. It results in large variations of lidar carrier-to-noise ratio (CNR). The 14 June night (N14, between 13 and 14 June) is relatively steady with weak wind conditions close to the surface that increase with height following a lognormal law profile. The 15 June night (N15) is characterized by a strong nocturnal jet with $V>10 \mathrm{~m} \mathrm{~s}^{-1}$ for $z>0.1 \mathrm{~km}$ up to $1 \mathrm{~km}$. It is worth noticing that despite low lidar CNR around 0500 local time, we can identify downward slanting aerosols structures that led us to suspect significant subsidence motion during this night. During the night of 16 June (N16), a thunderstorm resulted in some rain around 0300 LT. Strong updrafts and downdrafts were identified in front of it (at 2200 and 0100 LT, respectively) and during the rain period (at 0200 and 0300 LT), which provided additional sources of turbulence during this night.

\section{CDIAL performances}

\section{a. Vertical velocity}

Following Frehlich et al. (1998), the power spectra of lidar or in situ vertical velocity $(w)$ is

$$
\Phi_{w}(\nu)=2 \frac{\Delta t}{M}\left|\mathrm{DFT}_{w}(\nu / \Delta \nu)\right|^{2},
$$

where DFT is the discrete Fourier transform, $\Delta \mathrm{t}$ is the time interval between the estimates, [i.e., $40 \mathrm{~s}$ (lidar) and $0.2 \mathrm{~s}$ (in situ)], $\Delta \nu=1 /(N \Delta t)$ is the frequency resolution, $N$ is the number of independent measurements, and $M$ is the number of vertical velocity estimates in a given time gate.

Figure 2 shows a comparison of velocity spectrum for lidar and in situ sensors for nighttime and daytime. Figures $2 \mathrm{a}-\mathrm{c}$ show that the spectra are in good agreement
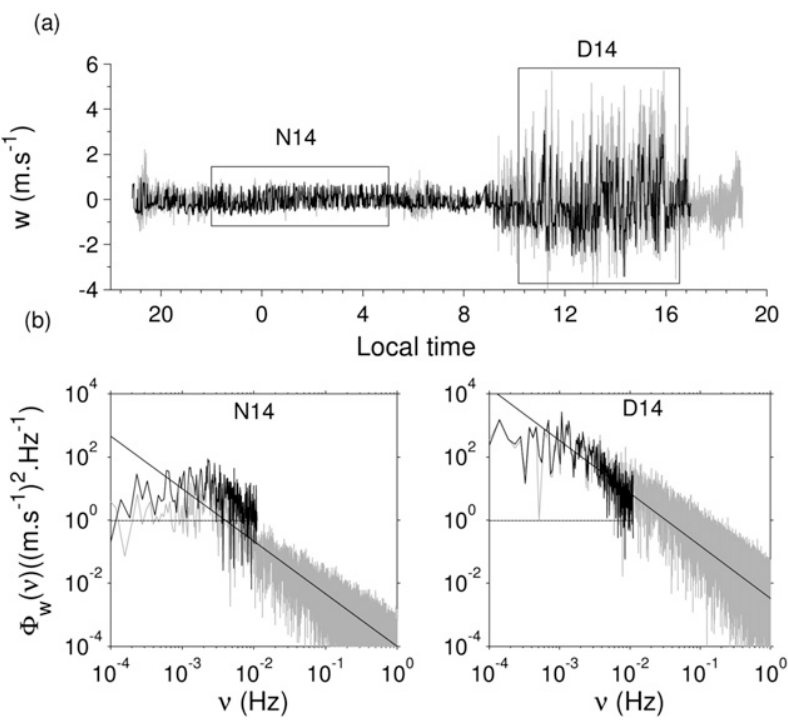

FIG. 2. Vertical velocity time series for (a) the sonic anemometer at $396 \mathrm{~m}$ and (b) the CDIAL at $375 \mathrm{~m}$ on 14 June. The corresponding spectra for the night N14 and day D14 are displayed. The gray line indicates the in situ sensor and the black line is for the lidar. The usual Kolmogorov $-5 / 3$ slope is indicated. The black dashed line represents the noise level.

in the CBL. The variance from lidar measurements seems slightly reduced, though (Fig. 2a). In the residual layer (nighttime), the natural variance of vertical velocity is in the same order of magnitude as the lidar noise variance. However, a turbulent spectrum peaking at $3 \times 10^{-3} \mathrm{~Hz}$ with a $-5 / 3$ slope in the inertial subrange is still apparent. From the spectra, we estimate instrumental noise and natural vertical velocity standard deviations (Frehlich et al. 1998; Gibert et al. 2007a), as reported in Table 1.

\section{b. $\mathrm{CO}_{2}$ mixing ratio}

To make a relevant comparison between $2-\mu \mathrm{m}$ CDIAL and in situ $\mathrm{CO}_{2}$ mixing ratio we average lidar estimates during $6 \mathrm{~h}$ for $\mathrm{N} 14$ and D14. As displayed in Fig. 3, it enables us to make for the first time a comparison of $\mathrm{CO}_{2}$ profiles between a $2-\mu \mathrm{m}$ CDIAL and in situ

TABLE 1. Standard deviation of vertical velocity and $\mathrm{CO}_{2}$ mixing ratio measurements. In situ data are from the 396-m high level of the WLEF tower. Lidar data are at $375 \mathrm{~m}$. The $\mathrm{CO}_{2}$ lidar measurement standard deviation is supposed to equal the noise variance. Time periods in 2007 are 14 Jun [N14 (2200-0500), D14 (1030-1630)]; 15 Jun [N15 (2200-0400), D15 (1100-1700)]; and 16 Jun [N16 (2100-0300), D16 (1130-1730)].

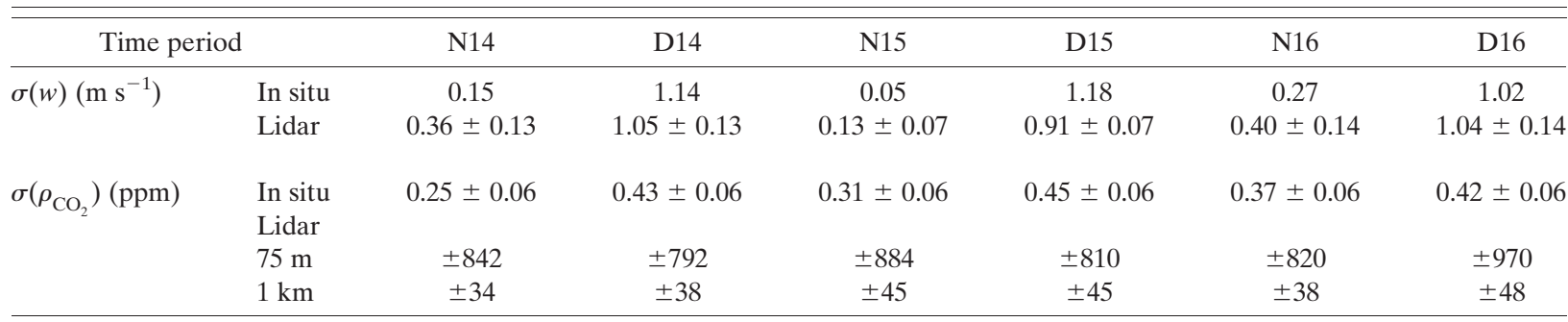


(a)
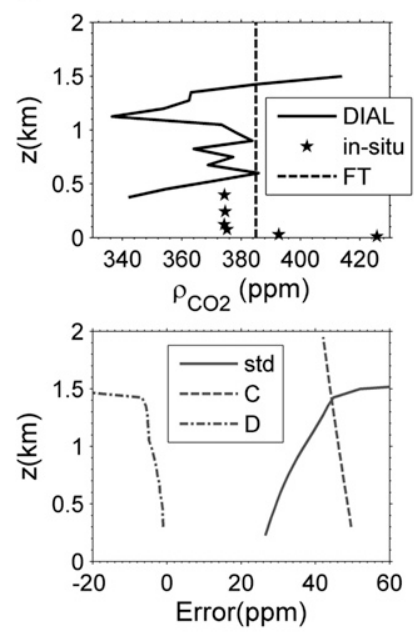

(b)
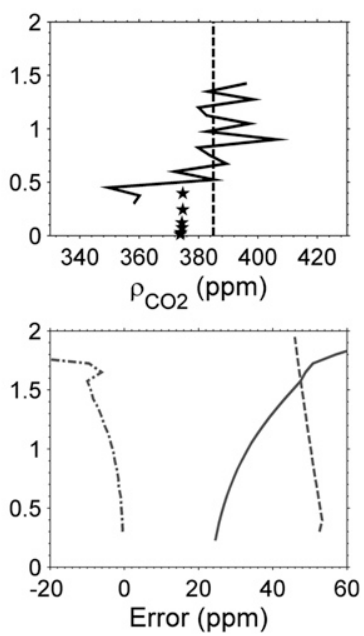

FIG. 3. The 6-h, 150-m averaged CDIAL $\mathrm{CO}_{2}$ mixing ratio profiles for (a) N14 and (b) D14 compared with the in situ profile up to $396 \mathrm{~m}$. The free troposphere (FT) mixing ratio is indicated with a dashed line. Corresponding (c) CDIAL standard deviation (std dev) and (d) bias profiles.

sensors up to $396 \mathrm{~m}$, the maximum height of the tower. Biases and standard deviation profiles have been calculated as well. The bias term, $C$, due to water vapor absorption [see Eq. (2)] is rather constant along the vertical according to an assumption of constant mixing ratio in the residual or convective boundary layers. The bias term $D$ and standard deviation increase with altitude as a result of a decrease of the Online SNR due to $\mathrm{CO}_{2}$ absorption.

After correction for potential biases, the N14 lidar $\mathrm{CO}_{2}$ profile agrees well with in situ data. For D14, the lidar $\mathrm{CO}_{2}$ mixing ratios increase with height. Notice that airborne $\mathrm{CO}_{2}$ measurements on 11 June 2007, conducted by the National Oceanic and Atmospheric Administration (NOAA) around the WLEF site $\left(46.00^{\circ} \pm 0.05^{\circ} \mathrm{N}, 90.17^{\circ} \pm\right.$ $0.03^{\circ} \mathrm{W}$ ) reported a free troposphere $\mathrm{CO}_{2}$ mixing ratio of $(384.5 \pm 0.4) \mathrm{ppm}$ from $2200 \mathrm{~m}$ up to $3900 \mathrm{~m}$. Such comparable values for $\mathrm{CO}_{2}$ mixing ratio in the CBL by lidar and free troposphere by aircraft can be explained by a thick and an active entrainment zone on D14 as displayed in Fig. 1a.

At time and range resolutions of $40 \mathrm{~s}$ and $75 \mathrm{~m}$, respectively, a white noise prevails in lidar measurements of $\mathrm{CO}_{2}$ mixing ratio (Table 1). The error in $\mathrm{CO}_{2}$ measurements is slightly larger than what was estimated previously (Gibert et al. 2008; see the standard deviation for resolutions of $1 \mathrm{~km}$ and $2 \mathrm{~min}$ ). It is mainly due to a lower $\mathrm{CO}_{2}$ absorption (i.e., the on-line was move to the edge of the $\mathrm{CO}_{2}$ absorption line in order to increase the range of measurements). The standard deviation decreases as the square root of time and range averaging as expected. The online laser frequency jitter of $1.9 \mathrm{MHz}$ contributes to $0.2 \mathrm{ppm}$ to standard deviation for a 40 -s averaging. Other uncertainties and biases as quantified in Gibert et al. (2008) are negligible.

\section{Turbulent fluctuations of $\mathrm{CO}_{2}$ mixing ratio and vertical velocity in the $A B L$ from in situ sensors}

To derive the incidence of turbulent fluctuations in $\mathrm{CO}_{2}$ flux retrievals by lidar, a necessary step is an estimate of the relevant space and time integral scales (see section 6). Here the turbulent fluctuations are analyzed using high-time-resolution and high-accuracy in situ probes. The standard deviation of vertical velocity is driven by surface heat flux variations. It is the largest in the middle of the CBL following the similarity law as displayed in Fig. 4. Mean velocity fluctuations are around $\pm 1 \mathrm{~m} \mathrm{~s}^{-1}$. During the three nights, the vertical velocity fluctuations at $396 \mathrm{~m}$ can be as low as $\pm 0.03 \mathrm{~m} \mathrm{~s}^{-1}$ (N15 case), with large variations from one hour to another (not shown here), and can reach $\pm 0.5 \mathrm{~m} \mathrm{~s}^{-1}$ (N16 case). The daytime $\mathrm{CO}_{2}$ mixing ratio fluctuations are rather similar from day to day, with a value around $\pm 0.5 \mathrm{ppm}$. Large $\mathrm{CO}_{2}$ variations are seen during the morning transition to be up to $8 \mathrm{ppm}$ at $122 \mathrm{~m}$ and $3 \mathrm{ppm}$ at $396 \mathrm{~m}$ (D16). These are due to the rising CBL and former nocturnal layer into the residual layer. In situ sensors at $396 \mathrm{~m}$ are in the residual layer during nighttime and $\mathrm{CO}_{2}$ mixing ratio turbulent fluctuations are usually as low as $\pm 0.2 \mathrm{ppm}$ with frequent increases up to $\pm 0.5 \mathrm{ppm}$ associated with either a nocturnal jet on $\mathrm{N} 15$ or a storm on N16. The similarity law for scalars predicts rather similar turbulent fluctuations in the whole convective and residual layers. In comparison to water vapor turbulent fluctuations $(\sim 5 \%$ of the mean value; Giez et al. 1999), it is clear that $\mathrm{CO}_{2}$ fluctuations $(\sim 0.1 \%)$ are very hard to reach for lidar today, even considering averaging over few hours and/or accumulation over longer ranges ( $1 \mathrm{~km}$ or so). However, the instrumental challenge for coherent lidar is in vertical velocity measurements at night when fluctuations as low as $0.03 \mathrm{~m} \mathrm{~s}^{-1}$ are observed. To achieve such a low figure, time averaging and range accumulation are required for lidar but some limitations are set by turbulence integral scale as discussed in section 6 .

\section{Space and time integral scales}

Time and space scales of turbulence are calculated using time and space covariance of vertical velocity and $\mathrm{CO}_{2}$ mixing ratio following Lenschow and Stankov (1986) (appendix B).

\section{a. Horizontal or time integral scale}

Figure 5a shows hourly time integral scale of vertical velocities $l_{w}^{(t)}$ from sonic anemometer and 2- $\mu$ m CDIAL data. During daytime for in situ sensor at $396 \mathrm{~m}, l_{w}^{(t)}$ 

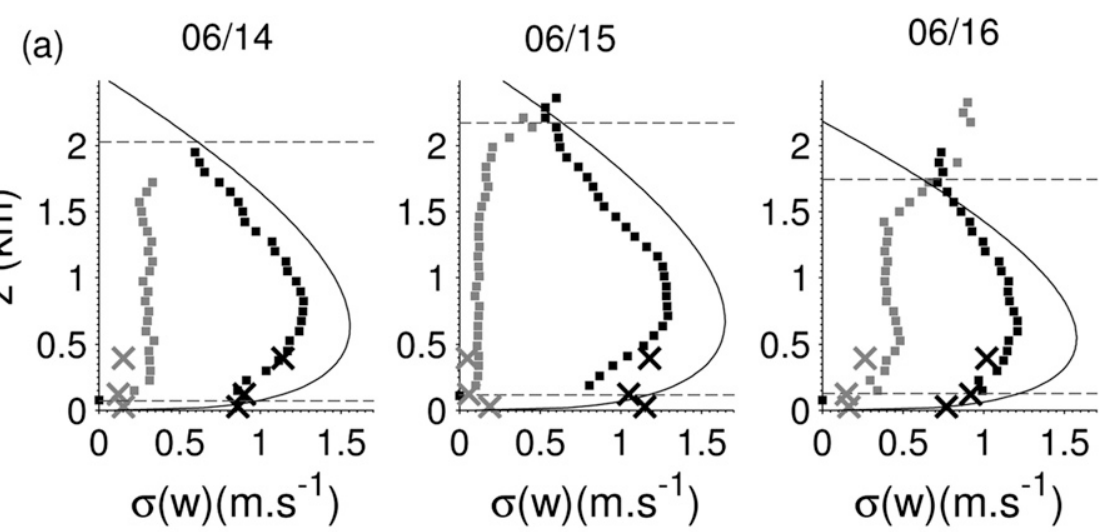

(b)
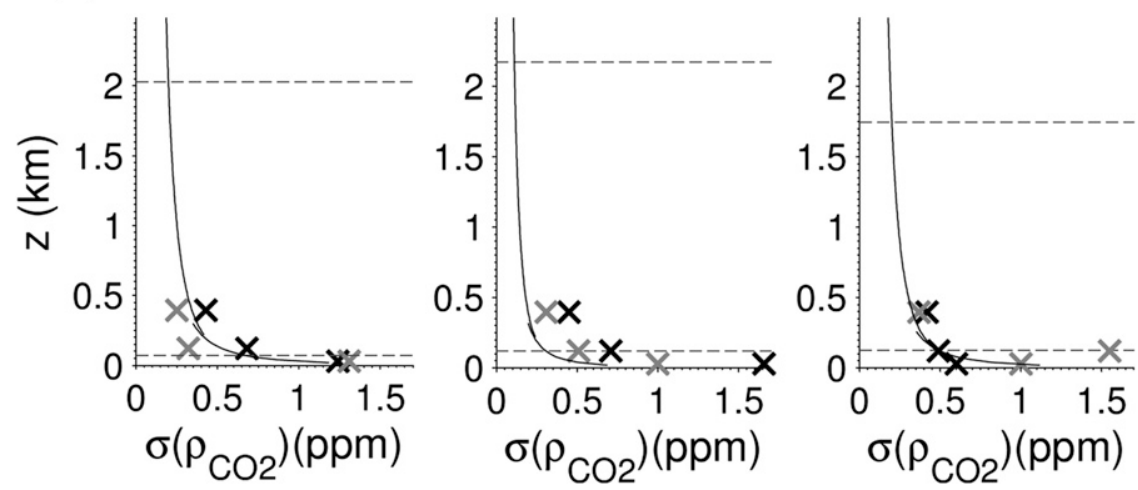

FIG. 4. (a) Vertical velocity and (b) $\mathrm{CO}_{2}$ mixing ratio natural standard deviation for the CDIAL (squares) and in situ sensors (crosses) for (left to right) 14, 15, and 16 June. Black and gray colors are for day and night, respectively. Theoretical laws from similarity are also displayed (black solid lines). Mean NL and CBL heights (dashed lines) are also displayed.

ranges between 30 and $90 \mathrm{~s}$. Comparison of lidar and in situ estimates are in good agreement. During nighttime large variations of $l_{w}^{(t)}$ occur. On N15, when a nocturnal jet occurred, $l_{w}^{(t)}$ ranges between 50 and $150 \mathrm{~s}$, whereas on N14 $l_{w}^{(t)}$ is lower than $50 \mathrm{~s}$. Close to the surface, at $30 \mathrm{~m}$, a diurnal cycle of $l_{w}^{(t)}$ can be seen. In the nocturnal boundary layer, the size of turbulent eddies is indeed much reduced by static stability.

Similar integral scales or coherent time of turbulence can be calculated for $\mathrm{CO}_{2}$ mixing ratio and for $\mathrm{CO}_{2}$ fluxes (appendix C). Note that $l_{\rho_{\mathrm{CO} 2}}^{(t)}$ is larger than $l_{w}^{(t)}$, especially during the night. The fluctuations of a scalar are linked not only to vertical motion but also to advection. During the day, $l_{w}^{(t)}, l_{\rho_{\mathrm{CO} 2}}^{(t)}$, and $l_{F_{\mathrm{CO} 2}}^{(t)}$ are comparable, meaning that buoyancy drives both velocity and scalar fluctuations in the CBL as expected.

In Fig. 6a, we analyze the vertical variations of the horizontal integral scale. Above $396 \mathrm{~m}$ and during daytime, $l_{w}^{(t)}$ usually increases with height and reaches a maximum in the middle of the CBL where thermals can be clearly defined (Kaimal et al. 1976; Lenschow et al. 1980; Gibert et al. 2007a). Using vertical profile of horizontal wind from lidar, our results confirm the results that for $z<z_{i} / 2, l_{w}^{(t)}$ increases with height according to $\sim\left(z z_{i}\right)^{1 / 2}$. For $z>z_{i} / 2, l_{w}^{(t)}$ decreases significantly with height when the thermals contours are not well delimited and cloud effects and entrainment are important near the CBL top. The $l_{w}^{(t)}$ profiles at nighttime seem to depend on horizontal wind speed profiles in the residual layer. An increase of the wind speed entails larger structures of turbulence. For example, the nocturnal jet during N15 results in the largest $l_{w}^{(t)}$ values in our dataset (Figs. 5a and 6a).

\section{b. Vertical integral scale}

We use the lidar vertical velocity profiles to estimate the vertical integral scale of turbulence $l_{w}^{(z)}$. Figure $5 \mathrm{~b}$ shows that at $375 \mathrm{~m}$ in the $\mathrm{CBL} l_{w}^{(z)}$ ranges between 100 and $250 \mathrm{~m}$. These values are smaller than those proposed in Lothon et al. (2006) but are in good agreement with Giez et al. (1999). At night, the integral scale is around $100 \mathrm{~m}$, except for N15. Large $l_{w}^{(z)}$ values are computed for N16 because of storm downdrafts and updrafts.

Figure $6 \mathrm{~b}$ shows that during daytime, $l_{w}^{(z)}$ is maximum in the middle of the CBL, as is $l_{w}^{(t)}$. Near the CBL top, $l_{w}^{(z)}$ decreases significantly with height, in agreement with 

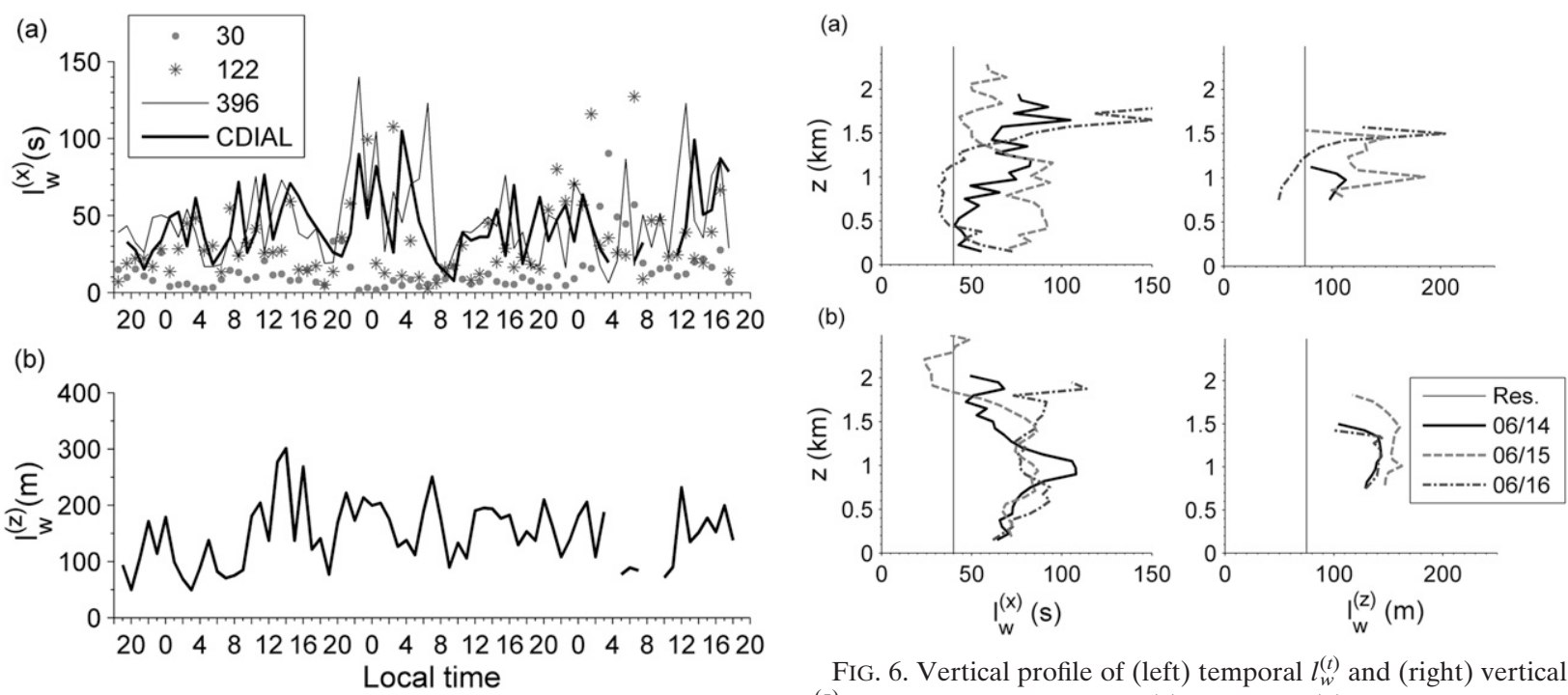

FIG. 6. Vertical profile of (left) temporal $l_{w}^{(t)}$ and (right) vertical $l_{w}^{(z)}$ velocity integral scales for (a) nights and (b) days using CDIAL

FIG. 5. (a) Hourly time integral scale of vertical velocities $l_{w}^{(t)}$ using sonic anemometer at 30 (circles), 122 (stars), and $396 \mathrm{~m}$ (thin solid line) and CDIAL data at $375 \mathrm{~m}$ (thick solid line). (b) Hourly vertical integral scale of vertical velocities $l_{w}^{(z)}$ at $z=1 \mathrm{~km}$. CDIAL vertical velocity resolution is $75 \mathrm{~m}$.

both compressed eddies (Kristensen et al. 1989; Lothon et al.2006) and decrease of large-scale coherence near the entrainment zone. A decrease of $l_{w}^{(z)}$ happens also when $z$ decreases. This result is in disagreement with Lothon et al., who found constant or increasing $l_{w}^{(z)}$ for decreasing $z$. Our results are consistent with an increase of rather small-scale turbulent structures closer to the ground. During the night and above $396 \mathrm{~m}, l_{w}^{(z)}$ seems to increase with the wind speed (N14) or subsidence large-scale structures (N15 and N16). For the following parts of this paper and for $l_{F_{\mathrm{CO}}}^{(t)}$, we assume that the flux vertical integral scale is nearly equal to the velocity vertical integral scale [i.e., $\left.l_{F_{\mathrm{CO}_{2}}}^{(z)} \approx l_{w}^{(z)}\right]$.

\section{First attempt to infer $\mathrm{CO}_{2}$ turbulent flux by lidar}

\section{a. Efficient spectral filtering accounting for integral scale cutoff}

Using the in situ data at $396 \mathrm{~m}$, we studied an efficient filtering technique accounting for integral scales cutoff (from section 6) to limit the losses on useful information and for limited biases on $\mathrm{CO}_{2}$ flux calculations.

The cross-spectrum of two different variables $w$ and $\rho_{\mathrm{CO}_{2}}$ is defined as

$$
\Phi_{F_{\mathrm{CO} 2}}(\nu)=\frac{\Delta t}{M} \operatorname{Re}\left[\operatorname{DFT}_{w}(\nu / \Delta \nu, t) \operatorname{DFT}_{\rho_{\mathrm{CO} 2}}(\nu / \Delta \nu, t)^{*}\right],
$$

where $\Phi_{F_{C O 2}}$ is the Fourier transform of the covariance between $c$ and $w(\mathrm{CCV})$ and $\mathrm{DFT}_{\rho \mathrm{CO} 2 *}$ is the complex

conjugate of $\mathrm{DFT}_{\rho \mathrm{CO} 2}$. The integral of the cospectrum over the whole frequency range yields $\mathrm{CCV}(0)$ (i.e., the vertical $\mathrm{CO}_{2}$ flux).

Figure 7 shows the spectra and cospectra from D14 for $\mathrm{CO}_{2}$ mixing ratio and vertical velocity time series using in situ data. The $-5 / 3$ inertial subrange is seen in $\mathrm{CO}_{2}$ and velocity spectra. The frequency of the expected maximum contribution to the cospectrum is the inverse of the temporal $\mathrm{CO}_{2}$ flux integral scale $l_{F_{\mathrm{CO} 2}}^{(t)}$. Following Kristensen et al. (1989) we display the frequency $\nu_{\max }$ where the main contributions to covariance occur. It is linked to the flux integral scale as $\nu_{\max }=1 /\left[2 \pi l_{F_{\mathrm{CO} 2}}^{(t)}\right]$. There is little contribution to the total flux at wavelengths smaller than the integral scale. As shown in Giez et al. (1999) for water vapor flux, $\nu_{\max }$ is an upper bound for contribution of the cospectrum to $\mathrm{CO}_{2}$ flux. Figure $7 \mathrm{~d}$ shows that during daytime the time resolution of the lidar (i.e., $40 \mathrm{~s}$ ) is smaller than the horizontal integral scale, and it is appropriate to get the main features of $\mathrm{CO}_{2}$ flux in the whole CBL. However, the slow decrease of the integral of $\Phi_{F_{\mathrm{CO} 2}}$ at high frequency entails significant biases on $F_{\mathrm{CO} 2}$ using low-time-resolution data, meaning that all the frequencies (i.e., eddies at different scales) contribute significantly to the daytime turbulent flux. For time averaging of 40, 80, and $160 \mathrm{~s}$ the corresponding bias is $16 \%, 29 \%$, and $41 \%$, respectively. These figures calculated at $396 \mathrm{~m}$ are used to correct the lidar $\mathrm{CO}_{2}$ flux estimates. This will result in overestimation of the $\mathrm{CO}_{2}$ flux because the biases are expected to be smaller in the middle of the CBL as $l_{w}^{(t)}$ is usually larger there than it is at $396 \mathrm{~m}$ (Fig. 6). 



FIG. 7. The D14 power spectra of (a) in situ vertical velocity and (b) $\mathrm{CO}_{2}$ mixing ratio at $396 \mathrm{~m}$, between 1100 and 1300 LT. (c) Cospectrum and (d) integral of the cospectrum. Black, light gray, and gray lines are for 0.2 -s data, 40-s averaged data, and 160-s rolling averaged data, respectively. The straight lines indicates the expected $-5 / 3$ law in the inertial subrange. The $v_{\max }$ marks the predicted maximum of the cospectral contribution to the flux. The inverse of the cross-covariance integral scale from Fig. 6a is also indicated.

\section{b. First $\mathrm{CO}_{2}$ flux measurements by lidar}

The mean $\mathrm{CO}_{2}$ fluxes are estimated in 2-h time gates for simultaneous $\mathrm{CO}_{2}$ mixing ratio and vertical velocity time series at various range accumulation and time averaging [i.e., $150 \mathrm{~m}$ and $80 \mathrm{~s}$ (squares); $300 \mathrm{~m}$ and $160 \mathrm{~s}$ (stars)] in order to reduce as much as possible the statistical error of $\mathrm{CO}_{2}$ mixing ratios. The results are displayed in Fig. 8. The $\mathrm{CO}_{2}$ measurements are corrected for biases $C$ and $D$ [see Eq. (2)]. The 2-h flux estimates are then averaged over $6 \mathrm{~h}$ and $1200 \mathrm{~m}$ (for a range gate from 300 to $1500 \mathrm{~m}$ ). Using in situ data we corrected the lidar $\mathrm{CO}_{2}$ fluxes from biases due to $\mathrm{H}_{2} \mathrm{O}$ flux $\left[F_{C}\right.$ in Eq. (3)] and lidar data averaging (section 7a).

During daytime, and despite large statistical errors, the lidar $\mathrm{CO}_{2}$ flux estimates are significant and negative, as are the in situ fluxes. $\mathrm{A} \mathrm{CO}_{2}$ uptake by vegetation creates a sink in the surface layer that corresponds to a negative $\mathrm{CO}_{2}$ flux at the bottom of the CBL. The free troposphere represents a source of $\mathrm{CO}_{2}$ for the $\mathrm{CBL}$ as reported in section 4 and therefore we expect a negative flux of $\mathrm{CO}_{2}$ at the top of the CBL.

During nighttime, the increase of $\mathrm{CO}_{2}$ mixing ratio at the different levels below $244 \mathrm{~m}$ represents the buildup of $\mathrm{CO}_{2}$ concentration in the nocturnal layer due to positive $\mathrm{CO}_{2}$ surface flux associated with vegetation respiration (Fig. 8a). At the top of the residual layer, and because of larger free tropospheric $\mathrm{CO}_{2}$ mixing ratio than in the residual layer, the entrainment flux is expected to be
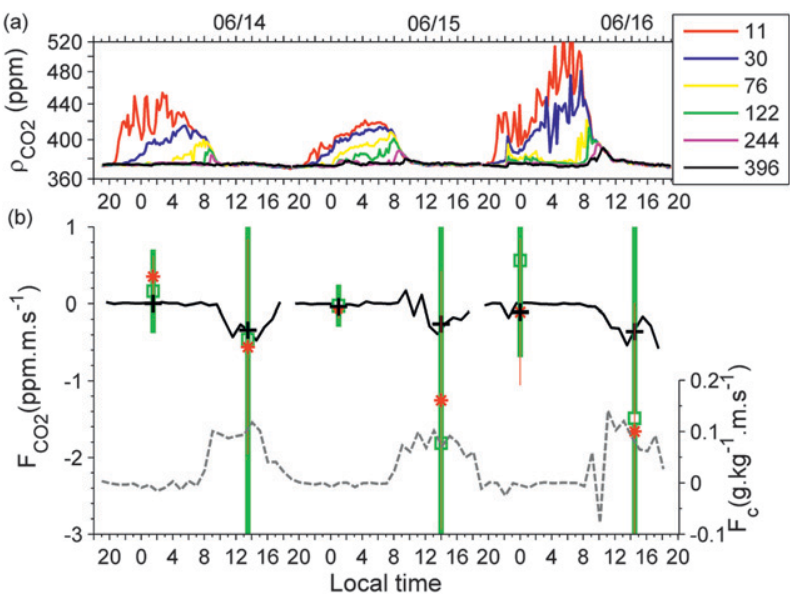

FIG. 8. (a) The $\mathrm{CO}_{2}$ in situ mixing ratio measurements at 11,30 , $76,122,244$, and $396 \mathrm{~m}$. (b) In situ eddy covariance $\mathrm{CO}_{2}$ flux at $396 \mathrm{~m}$ (black solid line) and 1.2-km ABL-mean lidar $\mathrm{CO}_{2}$ flux estimates using the eddy covariance technique on $150-\mathrm{m}, 80-\mathrm{s}$ (green squares) and 300-m, 160-s (red stars) rolling averaged lidar $\mathrm{CO}_{2}$ mixing ratio and vertical velocity measurements. The gray dashed line is for the in situ water vapor eddy covariance flux at $396 \mathrm{~m}$ used to correct $\mathrm{H}_{2} \mathrm{O}$ bias on $\mathrm{CO}_{2}$ flux measurements.

negative. These considerations explain the in situ negative $\mathrm{CO}_{2}$ flux measured during N15 and N16. Lidar flux measurements using 300-m range and 160 -s averaging are in good agreement with a global negative $\mathrm{CO}_{2}$ flux in the whole RL (especially in the N15 and N16 cases when $F_{C}$ is negligible).

From Eq. (3) we infer the random instrumental error in eddy flux measurements (Giez et al. 1999):

$$
\begin{aligned}
\sigma_{F_{\mathrm{CO} 2, \text { inst }}}^{2}= & \frac{\Delta t}{T} \frac{\Delta z}{Z}\left(\sigma_{w, \text { atm }}^{2} \sigma_{\rho_{\mathrm{CO} 2, \text { inst }}}^{2}+\sigma_{\rho_{\mathrm{CO} 2, \text { atm }}}^{2} \sigma_{w, \text { inst }}^{2}\right. \\
& \left.+\sigma_{\rho_{\mathrm{CO} 2 \text {,inst }}^{2}}^{2} \sigma_{w, \text { inst }}^{2}\right)
\end{aligned}
$$

where $\Delta t$ and $\Delta z$ correspond to the time and space resolution of lidar measurements and $T$ and $Z$ are respectively the time and space resolution of eddy covariance flux measurements.

The standard deviation of CDIAL flux estimates is approximately $850 \%$ during the daytime and $250 \%$ for N15 and N16 turbulent nights (Table 2). Large turbulent scales due to subsidence motion increase the lidar $\mathrm{CO}_{2}$ flux estimates as a result of intermittent and large $\mathrm{CO}_{2}$ fluctuations (between 0.5 and 2 ppm during N15 and N16). The experimental standard deviation calculated with the 2-h lidar $\mathrm{CO}_{2}$ flux profiles and the theoretical standard deviation calculated with Eq. (6) give similar results. As a result, we are able to predict the performances of future instrument for accurate $\mathrm{CO}_{2}$ flux measurements as discussed in section 8. Instrumental error due to online frequency jitter contributes to less than $1 \%$ of standard 
TABLE 2. The 6-h averaged in situ and lidar eddy covariance flux measurements. Lidar flux estimates are averaged vertically over $1.2 \mathrm{~km}$ in the ABL. The lidar fluxes measurements are corrected from biases due to CDIAL data averaging (section 6a) and from water vapor flux $\left(F_{C}\right)$. These biases are estimated using in situ data at $396 \mathrm{~m}$. Standard deviations of CDIAL fluxes are calculated experimentally and theoretically using Eq. (7).

\begin{tabular}{|c|c|c|c|c|c|c|}
\hline & N14 & D14 & N15 & D15 & N16 & D16 \\
\hline In situ $\mathrm{CO}_{2}$ flux $\left(\mathrm{ppm} \mathrm{m} \mathrm{s}{ }^{-1}\right)$ & $3.7 \times 10^{-3}$ & -0.34 & -0.04 & -0.26 & -0.11 & -0.36 \\
\hline CDIAL $\mathrm{CO}_{2}$ flux (ppm m s $\mathrm{m}^{-1}$ ) & 0.35 & -0.73 & -0.06 & -2.07 & -0.09 & -1.75 \\
\hline Space and time resolution of CDIAL data & $150 \mathrm{~m}, 80 \mathrm{~s}$ & $150 \mathrm{~m}, 80 \mathrm{~s}$ & $300 \mathrm{~m}, 160 \mathrm{~s}$ & $150 \mathrm{~m}, 80 \mathrm{~s}$ & $300 \mathrm{~m}, 160 \mathrm{~s}$ & $150 \mathrm{~m}, 80 \mathrm{~s}$ \\
\hline \multicolumn{7}{|l|}{ Statistical error $\left(\mathrm{ppm} \mathrm{m} \mathrm{s}^{-1}\right)$} \\
\hline Experimental & 0.54 & 2.81 & 0.11 & 3.20 & 0.95 & 4.72 \\
\hline Theoretical & 0.76 & 3.03 & 0.21 & 3.05 & 0.42 & 4.27 \\
\hline \multicolumn{7}{|l|}{ Corrected biases (ppm m s${ }^{-1}$ ) } \\
\hline$F_{C}$ & 0.190 & -0.270 & 0.008 & -0.255 & 0.020 & -0.260 \\
\hline Signal averaging & $-1.4 \times 10^{-3}$ & +0.099 & $-5 \times 10^{-4}$ & +0.098 & -0.013 & +0.109 \\
\hline
\end{tabular}

deviation and is therefore negligible. A main source of random error in eddy covariance flux measurements is called the sampling error (Lenschow and Stankov 1986; Giez et al. 1999; Engelmann et al. 2008):

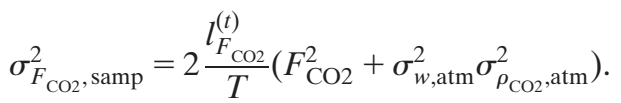

It depends on the number of dominant eddies or integral scales in the time interval $T$ to calculate the $\mathrm{CO}_{2}$ flux. In our cases, $T$ is quite large $(>2 \mathrm{~h})$ so this error is negligible and below $0.5 \%$.

The bias $F_{C}$ due to water vapor absorption is corrected. Notice that it contributes to nearly half the lidar $\mathrm{CO}_{2}$ flux estimates. This outlines the importance of proper location for the on- and off-laser lines. The corrected biases due to signal averaging (section $7 \mathrm{a}$ ) range between $30 \%$ and $40 \%$ during daytime and are lower than $10 \%$ for $\mathrm{N} 15$ and $\mathrm{N} 16$.

\section{Evaluation of future 2- $\mu \mathrm{m}$ CDIAL for accurate $\mathrm{CO}_{2}$ turbulent fluxes}

\section{a. Requirements on $\mathrm{CO}_{2}$ and velocity measurements}

Signal averaging can be used to decrease the instrumental statistical error on $\mathrm{CO}_{2}$ flux measurements as long as the conditions on time and space integral scales of $\mathrm{CO}_{2}$ turbulent flux [i.e., $\Delta z<l_{F_{\mathrm{CO} 2}}^{(z)}$ and $\Delta t<l_{F_{\mathrm{CO} 2}}^{(t)}$ ] are fulfilled to result in negligible biases with regard to flux measurements. The lower bound for lidar vertical range resolution is $150 \mathrm{~m}$ (Fig. 6). To estimate a lower bound for lidar time accumulation we use in situ data at $396 \mathrm{~m}$ to calculate $\mathrm{CO}_{2}$ turbulent flux with different time resolution in a $T$-time gate of $2 \mathrm{~h}$ (Fig. 9). The 2-h time gate is chosen as a compromise to have a negligible sampling error [see Eq. (7)] and to keep relevant flux measurements during the morning or evening transition. Similar results have been obtained during daytime. A smaller time averaging than $10 \mathrm{~s}$ enables us to keep the biases below $10 \%$. It is taken as a requirement for lidar $\mathrm{CO}_{2}$ flux measurements. A lower time resolution can be used during windy nights, especially during the N15 case when the bias is lower than $4 \%$ for a 1 -min averaging.

To obtain a lower bound for lidar $\mathrm{CO}_{2}$ and velocity standard deviation, we add $\mathrm{CO}_{2}$ and velocity random error variances on 10-s averaged in situ data and calculate the resulting standard deviation for 2-h average flux estimates. Figure 10 displays the results for the N14 and D14 cases. During daytime, Fig. 10b shows that limited $\mathrm{CO}_{2}$ mixing ratio precision as low as 15 ppm (i.e., 50 times the $\mathrm{CO}_{2}$ turbulent fluctuations reported in section 5 for in situ probes, with $\Delta t<10 \mathrm{~s}$ and $\Delta z<150 \mathrm{~m}$ ) is sufficient to reach an $F_{\mathrm{CO}}$ relative standard deviation lower than $50 \%$. Here, $50 \%$ is taken here as an arbitrary bound for relevant $\mathrm{CO}_{2}$ flux measurement. During the night, this precision will also be sufficient for highly turbulent conditions (N15 and N16) similar to those observed during daytime. For N14 stable conditions in the residual layer, Fig. 10a shows that a 2-ppm precision is required (i.e., 6 times the $\mathrm{CO}_{2}$ fluctuations reported by in situ probes).

The instrumental error on vertical velocity has a negligible impact on eddy covariance flux error as long as the noise standard deviation remains lower than the natural standard deviation (i.e., 0.1 and $1 \mathrm{~m} \mathrm{~s}^{-1}$ for N14 and D14, respectively).

\section{b. Dimension of a future 2- $\mu m$ CDIAL for accurate $\mathrm{CO}_{2}$ fluxes}

The precision of the $\mathrm{CO}_{2}$ mixing ratio relies on the number of independent samples in a range gate (notice the coherence time is limited by the laser pulse duration; see Bruneau et al. 2006), whereas the accuracy with regard to velocity relies on the precision in the spectrum of the heterodyne signal. For simultaneous velocity and concentration measurements, a compromise is needed for similar accuracies in the time and spectral domains. Figure 10 shows that accuracy in $\mathrm{CO}_{2}$ mixing ratio measurements 




FIG. 9. Bias on 2-h mean $\mathrm{CO}_{2}$ flux estimates for different time resolutions of in situ data at $396 \mathrm{~m}$.

demands short duration pulses ( $<100 \mathrm{~ns})$ to increase the number of samples and accuracy in the time domain.

Using the lidar equation and assuming the same off- and on-line instrumental constant $K$, energies $E$, heterodyne efficiencies $\gamma_{H}$, backscatter coefficient $\beta$, and atmospheric transmission $T_{\text {at }}$ except for the $\mathrm{CO}_{2}$ absorption $\left(T_{\mathrm{CO} 2}\right)$, we can write (Gibert et al. 2008)

$$
\begin{gathered}
\mathrm{CNR}_{\text {on }}=\mathrm{CNR}_{\text {off }} T_{\mathrm{CO} 2}^{2} \\
\mathrm{CNR}_{\text {off }}=\mathrm{KE} \gamma_{H} \beta T_{\mathrm{at}}^{2} / z^{2}
\end{gathered}
$$

The $\mathrm{CO}_{2}$ lidar standard deviation at $z+\Delta z / 2$ can be calculated by

$$
\sigma\left(\rho_{\mathrm{CO} 2}\right) / \rho_{\mathrm{CO} 2}=\left[\mathrm{SNR}_{\mathrm{on}}^{-2}(z)+\operatorname{SNR}_{\mathrm{off}}^{-2}(z)+\operatorname{SNR}_{\mathrm{on}}^{-2}(z+\Delta z)+\operatorname{SNR}_{\mathrm{off}}^{-2}(z+\Delta z) /\left(2 n_{\mathrm{air}} \Delta \tilde{\sigma}_{\mathrm{CO} 2} \Delta z\right)\right]^{1 / 2}
$$

where the SNR (which accounts for speckle and detection noise) is calculated from experimental CNR, using an analytical expression from Rye and Hardesty (1997):

$$
\mathrm{SNR}=\sqrt{M_{s} M_{t}} /\left(1+\mathrm{CNR}^{-1}\right) .
$$

Here $M_{t}=\sqrt{1+\left(\Delta t / T_{c}\right)^{2}}$ is the number of coherence cells in a range gate, assuming a Gaussian pulse of duration $T_{c}$ and a rectangular range gate of duration $\Delta t$, and $M_{s}$ is the number of shot-pair on-offs.

Numerical simulations were performed to estimate the precision of the $\mathrm{CO}_{2}$ mixing ratio as a function of the number of independent samples $M_{t} M_{s}$. The lidar time and range resolution are $10 \mathrm{~s}$ and $150 \mathrm{~m}$, respectively. Figure 11 displays the results at $z=1 \mathrm{~km}$. Here $T_{\text {at }}$ and $T_{\mathrm{CO} 2}$ are calculated using standard meteorological atmosphere profiles and new spectroscopic data for the $\mathrm{R} 30 \mathrm{CO}_{2}$ absorption line (Joly et al. 2009). The R30 line is more favorable than the $\mathrm{R} 22$ line used in the experiments described here. The on-laser line is located at the center of the $\mathrm{CO}_{2}$ absorption line. The laser pulse duration is $50 \mathrm{~ns}$, which entails $M_{t} \sim 20$. The heterodyne efficiency is $10 \%$ and $\beta=5 \times 10^{-7} \mathrm{~m}^{-1} \mathrm{sr}^{-1}$ so that we can display additional $E-\mathrm{PRF}$ axes corresponding to the $\mathrm{CNR}-M_{t} M_{s}$ ones in Fig. 11. Assuming a sequential emission of on- and off-lines, the bold $\sigma\left(\rho_{\mathrm{CO} 2}\right)=10 \mathrm{ppm}$ line is reached for a laser PRF $>2 \mathrm{kHz}$ or $E>2 \mathrm{~mJ}$, and a mean power PRF $\times E>24 \mathrm{~W}$. In addition, Fig. 11 shows that $E<10 \mathrm{~mJ}$ and ERF $>4 \mathrm{kHz}$ are more favorable to decrease the total power of the laser emitter.

\section{Conclusions}

In this paper the requirements for accurate rangeresolved $\mathrm{CO}_{2}$ flux measurements in the atmospheric boundary layer by combined and simultaneous DIAL 
(a) $\mathrm{N} 14$ 0-2



(b) D14 12-14

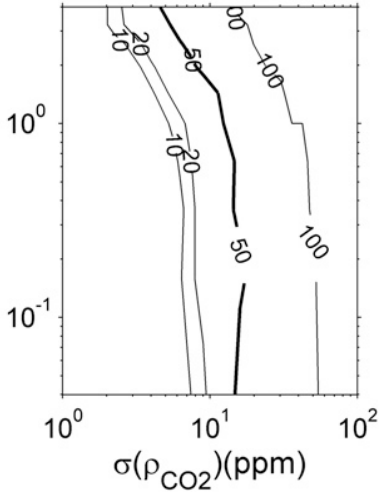

FIG. 10. The $\mathrm{CO}_{2}$ turbulent flux error (percent) as a function of vertical velocity and $\mathrm{CO}_{2}$ mixing ratio measurement standard deviations for 10-s time resolution and for (a) N14 and (b) D14. Flux time resolution is $2 \mathrm{~h}$.

and Doppler lidar techniques are quantitatively defined in terms of accuracy and time and space resolution. It is shown that the turbulent fluctuations of $\mathrm{CO}_{2}$ mixing ratio amount to $\sim 0.3$ and $0.5 \mathrm{ppm}$ during night and day, respectively, whereas the vertical velocity fluctuations are around $\sim 0.1 \mathrm{~m} \mathrm{~s}^{-1}$ and $1 \mathrm{~m} \mathrm{~s}^{-1}$ during night and day, respectively. Time and space resolution of the lidar measurements is constrained (i.e., limited) by relevant time and space integral scales that are determined by the size of coherent structures of turbulence. Despite a horizontal integral scale larger than $50 \mathrm{~s}$ in the convective $\mathrm{BL}$, it is found that shorter lidar time resolution (i.e., $<10 \mathrm{~s}$ ) is needed to avoid significant biases on $\mathrm{CO}_{2}$ flux estimates. During the night, the integral scale varies over two orders of magnitude, from $3 \mathrm{~s}$ to few minutes, depending on the occurrence of nocturnal jet or subsidence motion. The vertical integral scale is around $150 \mathrm{~m}$ in the CBL and can be lower than $100 \mathrm{~m}$ during the night. It is shown that the horizontal and vertical integral scales are the longest in the middle of the CBL.

Despite the limitation with regard to $\mathrm{CO}_{2}$ mixing ratio measurements by lidar compared to turbulent fluctuations (as reported by in situ sensors), we were able to report preliminary mean lidar $\mathrm{CO}_{2}$ flux measurements in the ABL with time and space resolutions of $6 \mathrm{~h}$ and $1200 \mathrm{~m}$, respectively. Depending on the turbulent fluctuations of $\mathrm{CO}_{2}$ mixing ratio, the $\mathrm{CO}_{2}$ flux error by CDIAL ranges between $250 \%$ for jet-disturbed nights and $850 \%$ during the day. These large uncertainties are reported for current CDIAL, which is not designed for the purpose of $\mathrm{CO}_{2}$ flux retrieval. Biases due to parasitic water vapor absorption and signal averaging were corrected using in situ data. This drawback can be avoided for CDIAL instruments properly designed for $\mathrm{CO}_{2}$ flux measurements. In this respect, numerical simulations

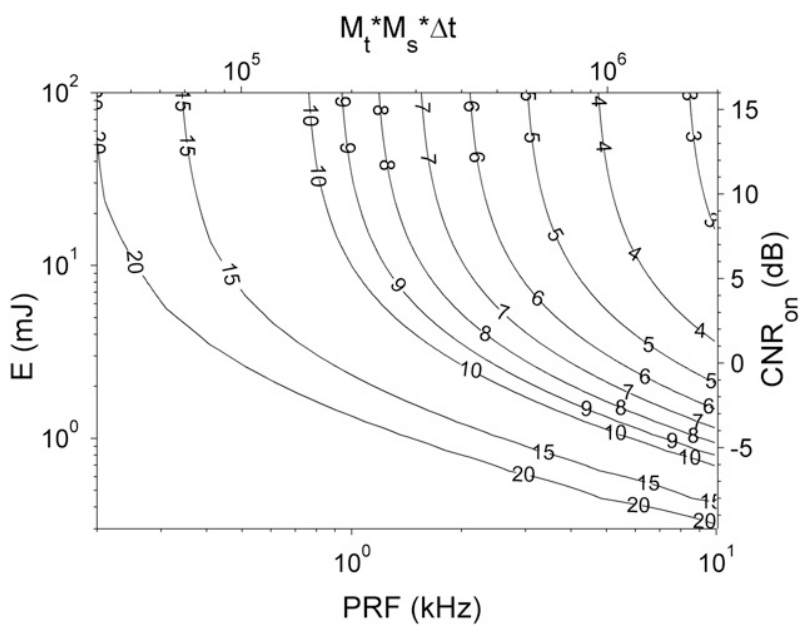

FIG. 11. The CDIAL $10-\mathrm{s}, 150-\mathrm{m}$ averaged $\mathrm{CO}_{2}$ mixing ratio standard deviations (ppm) as a function of on-line CNR $(\mathrm{dB})$ or laser pulse energy $(\mathrm{mJ})$ and the number of independent samples or laser pulse repetition frequency $(\mathrm{kHz})$.

using in situ $\mathrm{CO}_{2}$ and velocity measurements are conducted for the design of future CDIAL instrument. Although the turbulent fluctuations of $\mathrm{CO}_{2}$ mixing ratio are only a small portion of the mean value $(0.1 \%)$, we show that a $25-\mathrm{W} 2-\mu \mathrm{m}$ CDIAL operating with a 2-h time integration and $150-\mathrm{m}$ range resolution can retrieve accurate $\mathrm{CO}_{2}$ flux estimates (better than $50 \%$ ) as long as the $\mathrm{CO}_{2}$ mixing ratio instrumental error is smaller than $10 \mathrm{ppm}$ and the vertical velocity error is lower than fluctuations over a time period of $10 \mathrm{~s}$.

Acknowledgments. This research was funded by the NASA Instrument Incubator Program and NASA Laser Risk Reduction Program. We thank R. Strand and J. Ayers of the Wisconsin Educational Communications Board for hosting the lidar at the WLEF tower.

\section{APPENDIX A}

\section{Similarity Laws to Predict Vertical Velocity and Scalar Variances in the CBL}

The similarity law for vertical velocity variance in the CBL can be calculated using Stull (1988):

$$
\overline{w^{\prime 2}}=1.8 w_{*}^{2}\left(z / z_{i}\right)^{2 / 3}\left(1-0.8 z / z_{i}\right)^{2},
$$

where $w_{*}=\left(g z_{i} \overline{w^{\prime} \theta_{0}^{\prime}} / \bar{\theta}\right)^{1 / 3}$ is the free-convection scaling velocity, $\overline{w^{\prime} \theta_{0}^{\prime}}$ the in situ surface heat flux (calculated at $30 \mathrm{~m}), \bar{\theta}$ the mean potential temperature in the CBL, and $z_{i}$ the top of the CBL.

The theoretical turbulence variance of a scalar concentration like $\mathrm{CO}_{2}$ in the $\mathrm{CBL}$ can also be estimated using Moeng and Wyngaard (1984): 

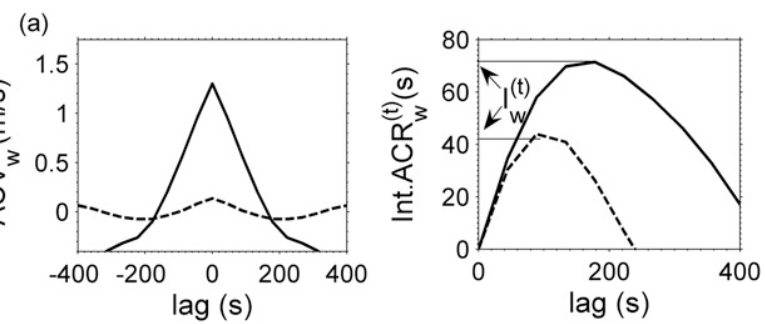

(b)
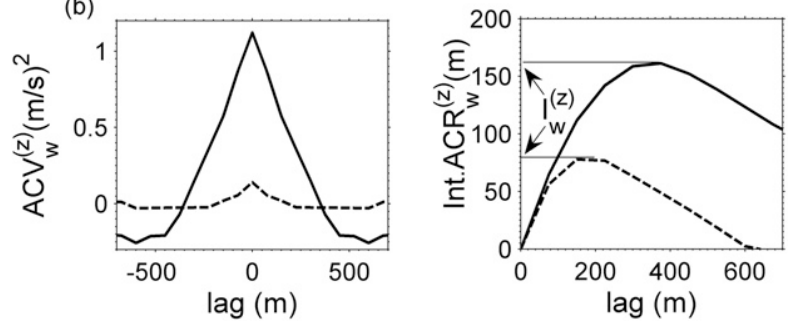

FIG. B1. (a) (left) D14 (solid line) and N14 (dashed line) time autocovariance function of CDIAL vertical velocity at $375 \mathrm{~m}$ $\left(\mathrm{ACV}_{w}^{(t)}\right)$ and (right) integrals of the autocorrelation functions $\left(\mathrm{ACR}_{w}^{(t)}\right)$. The time-integral scale is defined as the maximum of the integral (b) As in (a), but for the vertical integral scale calculation.

$$
\overline{\rho_{\mathrm{CO} 2}^{2}}=\left(\overline{w^{\prime} \rho_{\mathrm{CO}_{2}}^{\prime}} / w_{*}\right)^{2} f\left(z / z_{i}\right),
$$

where $\rho_{\mathrm{CO} 2}^{\prime}$ is the in situ $\mathrm{CO}_{2}$ surface flux (here calculated from the 30-m level of the WLEF tower) and $f\left(z / z_{i}\right)$ is the bottom-up variance function estimated from largeeddy simulation (LES) and equal to $\left(z / z_{i}\right)^{-0.9}$ for $z>0.1 z_{i}$ and $1.8\left(z / z_{i}\right)^{-2 / 3}$ for $z<0.1 z_{i}$.

\section{APPENDIX B}

\section{Turbulence Time and Space Scales-Methodology}

In this section, we investigate the turbulence characteristics of in situ and lidar observations using covariance techniques. The autocovariance (ACV) is used to separate signal variance due to space-correlated atmospheric processes from uncorrelated instrumental noise. For the atmospheric variable $c(x)$,

$$
\operatorname{ACV}_{c}(X)=\overline{c(x)^{\prime} c(x+X)^{\prime}},
$$

where $c(x)=\bar{c}+$, with $c^{\prime}(x)$ being the space-dependant fluctuation and $X$ the space lag. The overbar represents the mean in the range gate used to calculate the autocovariance.

For lidar measurements, Eq. (B1) becomes $\operatorname{ACV}_{c}(X)=$ $\overline{\langle c(x)\rangle^{\prime}\langle c(x+X)\rangle^{\prime}}$, where the angle brackets indicate both time and space lidar averaging. Since we used a ground-based instrument, the horizontal ACV is a function of time. Knowing that $\operatorname{ACV}_{c}(0)=\sigma_{c}^{2}=$



FIG. C1. Hourly time integral scale of vertical velocity, $\mathrm{CO}_{2}$ mixing ratio, and $\mathrm{CO}_{2}$ flux at $396 \mathrm{~m}$.

$\sigma_{c, \text { inst }}^{2}+\sigma_{c, \text { atm }}^{2}$, and using a Fourier transform to determine $\sigma_{c, \text { inst }}^{2}$ (Fig. 3), we can measure $\sigma_{c, \text { atm }}^{2}$. Then we can define the autocorrelation function (ACR) as $\operatorname{ACR}_{c}(X)=$ $A C V_{c}(X) / \sigma_{c, \mathrm{~atm}}^{2}$. The integral of this function is called the integral scale (IS) (Lenschow and Stankov 1986):

$$
l_{c}=\int_{0}^{\infty} \operatorname{ACR}_{c}(r) d r
$$

The first maximum of this integral is usually chosen to be the IS (Lenschow and Stankov 1986; Giez et al. 1999; Lothon et al. 2006). The IS is related to the dominant eddy size and enables us to determine the space and time scales of turbulence. A flux integral scale can also be defined using the covariance of two measured variables $c$ and $w$ :

$$
\operatorname{CCV}(X)=\overline{c(x)^{\prime} w(x+X)^{\prime}},
$$

where $\mathrm{CCV}(0)$ corresponds to the vertical flux of $c(x)$.

Figure B1 shows the time and space velocity autocovariance function and the corresponding integrals of autocorrelation functions. We use the maximum of the integral of $\mathrm{ACR}_{w}^{(t)}$ to define $l_{w}^{(t)}$. We use the same method to calculate $l_{w}^{(z)}$ rather than the exponential fit method used in Lothon et al. (2006), which was found to be less accurate in our cases.

\section{APPENDIX C}

\section{Comparison of Turbulence Integral Scales of Vertical Velocity, $\mathrm{CO}_{2}$ Mixing Ratio, and $\mathrm{CO}_{2}$ Flux}

Figure $\mathrm{C} 1$ shows a comparison of time integral scale for vertical velocity, $\mathrm{CO}_{2}$ mixing ratio, and $\mathrm{CO}_{2}$ flux using the method detailed in appendix B. During the day, $l_{\rho_{\mathrm{CO} 2}}^{(t)}, l_{w}^{(t)}$, and $l_{F_{\mathrm{CO} 2}}^{(t)}$ take similar values, which shows 
that eddies of the predominant size direct both velocity and scalar fluctuations in the CBL. During the night, no previous observations in the residual layer can help us to understand the large integral scales that we see for the $\mathrm{CO}_{2}$ mixing ratio. For $\mathrm{N} 15$ case, the nocturnal jet seems to explain similar increases in $l_{w}^{(t)}$ and $l_{\rho_{\mathrm{CO} 2}}^{(t)}$. An important result from Figure $\mathrm{C} 1$ is that $l_{F_{\mathrm{CO} 2}}^{(t)}$ varies from 5 to $1000 \mathrm{~s}$ with large variations from one hour to another, especially during the night and early morning. Large temporal scale correlation exists between $\mathrm{CO}_{2}$ mixing ratio and vertical velocity during the morning transition when $z_{i}$ reaches each level of the tower and when the overshoots bring the large $\mathrm{CO}_{2}$ mixing ratio from the former NBL into the RL. This is in good agreement with previous observations that conclude that entrainment plays a major role in $\mathrm{CBL} \mathrm{CO}_{2}$ drawdown during the morning transition (Vila-Guerau de Arellano et al. (2004); Gibert et al. 2007b).

\section{REFERENCES}

Berger, B. W., K. J. Davis, C. Yi, P. S. Bakwin, and C. L. Zhao, 2001: Long-term carbon dioxide fluxes from a very tall tower in a northern forest: Flux measurement methodology. $J$. Atmos. Oceanic Technol., 18, 529-542.

Bruneau, D., F. Gibert, P. H. Flamant, and J. Pelon, 2006: A complementary study of differential absorption lidar optimization in direct and heterodyne detections. Appl. Opt., 45, 4898-4908

Desai, A. R., P. V. Bolstad, B. D. Cook, K. J. Davis, and E. V. Carey, 2005: Comparing net ecosystem exchange of carbon dioxide between old-growth and mature forest in the upper Midwest USA. Agric. For. Meteor., 128, 33-55.

Engelmann, R., U. Wandiger, A. Ansmann, D. Müller, E. Zeromskis, D. Althausen, and B. Wehner, 2008: Lidar observations of the vertical aerosol flux in the planetary boundary layer. J. Atmos. Oceanic Technol., 25, 1296-1306.

Favreau, X., A. Delaval, P. H. Flamant, A. Dabas, and P. Delville, 2000: Four-element receiver for pulsed $10-\mu \mathrm{m}$ heterodyne Doppler lidar. Appl. Opt., 39, 2441-2448.

Frehlich, R., S. M. Hannon, and S. W. Henderson, 1998: Coherent Doppler lidar measurements of wind field statistics. Bound. Layer Meteor., 86, 233-256.

Gibert, F., P. H. Flamant, D. Bruneau, and C. Loth, 2006: Twomicrometer heterodyne differential absorption lidar measurements of the atmospheric $\mathrm{CO}_{2}$ mixing ratio in the boundary layer. Appl. Opt., 45, 4448-4458.

_ - J. Cuesta, J.-I. Yano, N. Arnault, and P. H. Flamant, 2007a: On the correlation between convective plume updrafts and downdrafts, lidar reflectivity and depolarization ratio. Bound.Layer Meteor., 125, 553-573.

- , M. Schmidt, J. Cuesta, P. Ciais, M. Ramonet, I. Xueref, E. Larmanou, and P. H. Flamant, 2007b: Retrieval of average $\mathrm{CO}_{2}$ fluxes by combining in situ $\mathrm{CO}_{2}$ measurements and backscatter Lidar information. J. Geophys. Res., 112, D10301, doi:10.1029/2006JD008190.

_ , P. H. Flamant, J. Cuesta, and D. Bruneau, 2008: Vertical $2-\mu \mathrm{m}$ heterodyne differential absorption lidar measurements of mean $\mathrm{CO}_{2}$ mixing ratio in the troposphere. J. Atmos. Oceanic Technol., 25, 1477-1497.

Giez, A., G. Ehret, R. L. Schwiesow, K. J. Davis, and D. H. Lenschow, 1999: Water vapor flux measurements from ground-based vertically pointed water vapor differential absorption and Doppler lidars. J. Atmos. Oceanic Technol., 16, 237-250.

Joly, L., and Coauthors, 2009: Laser diode absorption spectroscopy for accurate $\mathrm{CO}_{2}$ line parameters at $2 \mu \mathrm{m}$ : Consequences for space-based DIAL measurements and potential biases. Appl. Opt., 48, 5475-5483.

Kaimal, J. C., J. C. Wyngaard, D. A. Haugen, O. R. Coté, Y. Izumi, S. J. Caughey, and C. J. Readings, 1976: Turbulence structure in the convective boundary layer. J. Atmos. Sci., 33, 2152-2169.

Kiemle, C., and Coauthors, 2007: Latent heat flux profiles from collocated airborne water vapor and wind lidars during IHOP 2002. J. Atmos. Oceanic Technol., 24, 627-639.

Koch, G. J., and Coauthors, 2004: Coherent differential absorption lidar measurements of $\mathrm{CO}_{2}$. Appl. Opt., 43, 5092-5099. J. Y. Beyon, B. W. Barnes, M. Petros, J. Yu, F. Amzajerdian, M. J. Kavaya, and U. N. Singh, 2007: High-energy 2- $\mu \mathrm{m}$ Doppler lidar for wind measurements. Opt. Eng., 46, 116201, doi:10.1117/1.2802584.

— , and Coauthors, 2008: Side-line tunable transmitter for differential absorption lidar measurements of $\mathrm{CO}_{2}$ : Design and application to atmospheric measurements. Appl. Opt., 47, 944-956.

Kristensen, L., D. H. Lenschow, P. Kirkegaard, and M. Courtney, 1989: The spectral velocity tensor for homogeneous boundarylayer turbulence. Bound.-Layer Meteor., 47, 149-193.

Lenschow, D. H., and B. Stankov, 1986: Length scales in the convective boundary layer. J. Atmos. Sci., 43, 1198-1209.

, J. C. Wyngaard, and W. T. Pennell, 1980: Mean-field and second-moment budgets in a baroclinic, convective boundary layer. J. Atmos. Sci., 37, 1313-1326.

Lothon, M., D. H. Lenschow, and S. D. Mayor, 2006: Coherence and scale of vertical velocity in the convective boundary layer from a Doppler lidar. Bound.-Layer Meteor., 121, 521-536.

Menut, L., C. Flamant, J. Pelon, and P. H. Flamant, 1999: Urban boundary layer height determination from lidar measurements over the Paris area. Appl. Opt., 38, 945-954.

Moeng, C.-H., and J. C. Wyngaard, 1984: Statistics of conservative scalars in the convective boundary layer. J. Atmos. Sci., 41, 3161-3169.

Rye, B. J., and R. M. Hardesty, 1997: Estimate optimization parameters for incoherent backscatter heterodyne lidar. Appl. Opt., 36, 9425-9436.

Stull, R. B., 1988: An Introduction to Boundary Layer Meteorology. Kluwer Academic, 666 pp.

Toth, R. A., L. R. Brown, C. E. Miller, V. Malathy Devi, and D. Chris Benner, 2006: Line strength of ${ }^{12} \mathrm{C}^{16} \mathrm{O}_{2}: 4550-7000 \mathrm{~cm}^{-1}$. J. Mol. Spectrosc., 239, 221-242.

— C. E. Miller, V. Malathy Devi, D. C. Benner, and L. R. Brown, 2007: Air-broadened halfwidth and pressure shift coefficients of ${ }^{12} \mathrm{C}^{16} \mathrm{O}_{2}$ bands: $4750-7000 \mathrm{~cm}^{-1}$. J. Mol. Spectrosc., 246, 133-157.

Vila-Guerau de Arellano, J., B. Gioli, F. Miglietta, H. J. J. Jonker, H. K. Baltink, R. W. A. Hutjes, and A. A. M. Holtslag, 2004: Entrainment process of carbon dioxide in the atmospheric boundary layer. J. Geophys. Res., 109, D18110, doi:10.1029/ 2004JD004725.

Wang, W., K. J. Davis, B. D. Cook, M. P. Butler, and D. M. Ricciuto, 2006: Decomposing $\mathrm{CO}_{2}$ fluxes measured over a mixed ecosystem at a tall tower and extending to a region: A case study. J. Geophys. Res., 111, G02005, doi:10.1029/2005JG000093. 